\title{
Advances in Conceptual Ship Design Accounting for the Risk of Environmental Pollution
}

\author{
Yordan GARBATOV ${ }^{1}$, Petar GEORGIEV ${ }^{2}$ \\ 1- Centre for Marine Technology and Ocean Engineering (CENTEC), Instituto Superior Técnico, Universidade de Lisboa, Avenida Rovisco \\ Pais,1049-001 Lisbon, Portugal; \\ 2- Technical University of Varna, Studentska Str. 1, 9010 Varna, Bulgaria
}

Corresponding author contact: petar.ge@tu-varna.bg

\begin{abstract}
The present paper provides a thorough analysis of the prerequisites in adopting a new paradigm in the conceptual ship design accounting for the environmental pollution driven by maritime transportations. A survey of presently issued IMO environmental requirements outlines the framework within ship design solutions. Identified and carefully examined are several competing optimal design solutions, based on the energy efficiency design index introduced for shipbuilding, operation cost, and the resale costs at the end of the service life, which are used as input variables in a risk-based analysis. Reviewed are the immediate steps taken in the risk-based conceptual ship design to minimise the risk of environmental pollution while considering the life cycle assessment and energy efficiency of the ship propulsion system. Brought forth in the current paper are the results of a study into the concept design of series of containerships operating in the Black Sea for transporting 20, 40 and 45-foot containers aimed at identifying the main dimensions, capacity, visibility, freeboard, stability, bow, and stern design, propulsion complex and propeller design, control and manoeuvrability, seakeeping, energy efficiency design index, capital, and operational expenditures, that leads to the required fright rate for the ships in the range of 4,000 to 14,000 DWT. Accordingly, a bulk carrier's risk-based concept ship design methodology is employed for the ship life cycle assessment and energy efficiency in pursuance of the optimal design solution in reference to the energy efficiency design index as most applicable to shipbuilding, operation, and resale costs at the end of the service life, and used as input variables in the risk estimate.
\end{abstract}

Keywords: energy efficiency design index, environmental pollution, life cycle assessment, riskbased design

\section{$1 \quad$ Introduction}

Shipping is responsible for transporting about $90 \%$ of the global trade, and it is considered the least environmentally damaging mode of transportation (UNCTAD, 2020). The International Maritime Organization (IMO) continually issued resolutions and recommendations related to pollution prevention issues, including oil pollution, chemical pollution, sewage, garbage, air pollution, and Green House Gas (GHG) emissions, ballast water management, biofouling, anti-fouling systems, ship recycling, port reception facilities. The chronology of the MARPOL Annex VI amendments and recent studies concerning the emission evaluation from ships were discussed in (Blasco, et al., 2014).

The UNCTAD maritime database consists of 95,402 ships, and as of January 1, 2019, 7.66 per cent have installed or ordered a ballast water treatment system, 1.58 per cent have installed or ordered a system to reduce $\mathrm{SO}_{\mathrm{x}}$ emissions, and 0.53 per cent have installed or ordered a system to reduce $\mathrm{NO}_{\mathrm{x}}$ emissions (UNCTAD, 2020). These percentages show that the listed problems have not even been partially solved.

A study performed in (Smith, et al., 2016) analysed the $\mathrm{CO}_{2}$ emissions from international shipping and possible reduction targets and their associated pathways, exploring different scenarios by a broad range of possible futures related to the regulations, demand, and techno-economic characteristics. The analysed scenarios are regarded as a reasonable basis for further analyses.

Potential power setups, fuels, and hull designs capable of satisfying the future Energy Efficiency Design Index (EEDI) requirements were analysed in (Lindstad \& Bø, 2018), identifying that a slender 
hull in combination with a conventional engine is the most cost-competitive solution capable of satisfying the 2020 EEDI requirements, while hybrid power setups combined with slender designs are the most cost-competitive solution for the 2025 EEDI provisions.

IMO recognises the importance of adopting the risk assessment procedures in their decision process by defining the Formal Safety Assessment, FSA, (IMO, 2013; IMO, 2008a; IMO, 2005; IMO, 2002) as a systematic methodology in enhancing maritime safety, including the protection of life, health, marine environment, cargo and ship integrity by using risk and cost-benefit assessments.

Concerns are being raised because many of the already built ships cannot adequately meet the new requirements, where for example, the recent developments, as introduced by IMO, are likely to affect seriously the performance of the risk-based design (Papanikolaou, et al., 2009) and short sea shipping (Papadimitriou, et al., 2018).

A preliminary design of the Suezmax tanker incidental oil outflow risk due to ship collisions was presented in (Tan, et al,, 2019). The input variables include the main dimensions and block coefficient, longitudinal centre of buoyancy, and height of double bottom and width of double skin sides. The utility level, which is the weighted sum of steel weight, resistance, mean outflow, and cargo capacity or each of the design variants, were compared against different weighing factors. The amount of oil spill represented the environmental consequences of tanker collisions.

Recently, there has been a growing interest in the holistic ship design (Plessas, et al., 2018; Boulougouris, et al,, 2011; Papanikolaou, et al., 2009). A review of recently developed holistic design models is presented by Nowacki (2019), specifying that there are three main objectives addressed in each phase of the ship life cycle, i.e., economic efficiency, safety, and the environmental impact of the ship as an engineering product, are considered.

The growing sea transportation in the Arctic and Antarctic increased the risks of accidents. Bergström, et al., 2016 presented a framework for holistic goal- and risk-based arctic maritime transport design systems treated as a subsystem hierarchy.

A design framework based on the risk covering structural failure and hazards such as accidental spills, loss of cargo, ship, and crew members' failures was proposed (Garbatov, et al.,2018a). The framework was extended into a risk-centred maintenance methodology in determining the ship hull structural system's maintenance plan (Garbatov, et al., 2018b), thus endorsing its use in the early design stages.

The need for compliance with the EEDI requirements put many challenges to the designers and ship-owners. Energy efficiency is a merit function for multi-objective design optimisation for Aframax oil tankers and container ships (Boulougouris, et al., 2011). A parametric multi-objective optimisation procedure for Ro-Pax vessels and container ships, creating a reasonable and rationally supported balance between the economy, efficiency, and safety of the ship and the environment (Plessas, et al., 2018).

The present study identifies the advances in risk-based design and maritime transport's environmental requirements. The objective is to present the prerequisites for a risk-based conceptual ship design in pursuance of the optimal design solution in keeping with the EEDI, construction, operation, and scrap value at the end of the service life, used as input variables in the risk assessment.

To that effect, conducted was a study into the concept design of a series of containerships operating in the Black Sea to transport 20, 40 and 45-foot containers identifying the main dimensions for the ships in the range of 4,000 to 14,000 DWT. Accordingly, a bulk carrier's risk-based concept ship design methodology was also employed to help identify the optimal design solution determined by the energy efficiency design index, shipbuilding, operation, and resale costs at the end of the service life as input variables in the risk estimates.

\section{Environmental requirements for shipping}

From its first onboard use in 1912 until now, the heavy fuel oil (HFO) accounts for about $90 \%$ of the international energy shipping consumption (Fenhann, 2017). HFO is a product of the refining of crude oil to jet oil and gas oils. The HFO is very competitive in price but causes significant $\mathrm{CO}_{2}$ emis- 
sions and pollution by $\mathrm{NO}_{\mathrm{x}}, \mathrm{SO}_{\mathrm{x}}$, particulate matters $(\mathrm{PM})$ and methane. That makes it harmful to the environment, as it has high Sulphur content.

IMO estimated that the world fleet's fuel consumption doubled between 1990 and 2007, ranging from 170 million to more than 340 million tons per year. Of this amount, around $77 \%$ represents the consumption of HFO and 23\% of MGO (IMO, 2008b).

Some studies identify that the $\mathrm{CO}_{2}$ emissions of maritime shipping constitute $2.2 \%$ of the global $\mathrm{CO}_{2}$ emissions (Fenhann, 2017). This share has been decreasing since 2007, mainly due to the declining traffic and various shipping owners' measures.

Table 1 presents the world trade's $\mathrm{CO}_{2}$ emissions and different transport modes (Fenhann, 2017; Rodrigue, 2020). Despite the small amount of emissions originating from maritime transport, the measures taken are due to the world trade's large share.

Table 1. $\mathrm{CO}_{2}$ emission and volume of world trade by transport mode

\begin{tabular}{lccc}
\hline Mode of transport & $\begin{array}{c}\mathrm{CO}_{2} \text { emissions } \\
\mathrm{g} / \mathrm{km}\end{array}$ & $\begin{array}{c}\mathrm{CO}_{2} \text { emissions } \\
\mathrm{g} / \mathrm{tkm}\end{array}$ & $\begin{array}{c}\text { Share of World } \\
\text { Trade by } \\
\text { Volume, } \%\end{array}$ \\
\hline Aeroplane & 560 & 911 & 0.2 \\
Modern lorry or truck & 45 & 72 & 10 \\
Modern train & 18 & 28 & 89.8 \\
Modern ship & 3 & 13 & \\
\hline
\end{tabular}

Given the current state of environmental pollution and climate change, the entity responsible for regulating the transport, IMO, adopted in 2005 Annex VI of MARPOL 73/78 (DNV, 2009), pointing out the prevention of air pollution as a mandatory global standard.

The International Convention for the Prevention of Pollution from Ships, MARPOL, introduced rules regarding the limits of $\mathrm{CO}_{2}, \mathrm{NO}_{\mathrm{x}}, \mathrm{SO}_{\mathrm{x}}$ and $\mathrm{PM}$ (particulate matter).

\subsection{Sulphur oxides and particulate matter}

Emissions of sulphur oxides, $\mathrm{SO}_{\mathrm{x}}$ cause acidification of soil and water, resulting in severe damage to the environment, death of plants and animals, buildings, and other human-made structures (Kågeson, 1999) particulate matter being more closely related to health rather than environmental problems.

The rules that impose maximum limits on $\mathrm{SO}_{\mathrm{x}}$ and $\mathrm{PM}$ emissions are divided into two parts. The first is global in scope, limiting the sulphur content of fuel oils at levels of:

- $\quad 4.50 \% \mathrm{~m} / \mathrm{m}$ before January 1,2012 ,

- $\quad 3.50 \% \mathrm{~m} / \mathrm{m}$ from January 1, 2012 to January 1, 2020; and

- $0.50 \% \mathrm{~m} / \mathrm{m}$ as of January 1,2020 .

where $m$ refers to the unit of mass.

The second part covers regions identified as ECA (Emission Control Area) and SECA (Sulphur Emission Control Area), which are areas where mandatory special measures are required concerning ships' emissions to prevent, reduce, and control the air pollution due to $\mathrm{SO}_{\mathrm{x}}, \mathrm{NO}_{\mathrm{x}}$ and particulate matter in Fig. 1.

For vessels operating within SECA, the sulphur content of the fuel oil used on board must comply with the following limits:

- $1.50 \% \mathrm{~m} / \mathrm{m}$ before July 1,2010 ,

- $\quad 1.00 \% \mathrm{~m} / \mathrm{m}$ from July 1,2010 , to January 1,2015 ; and

- $0.10 \% \mathrm{~m} / \mathrm{m}$ as of January 1, 2015 . 

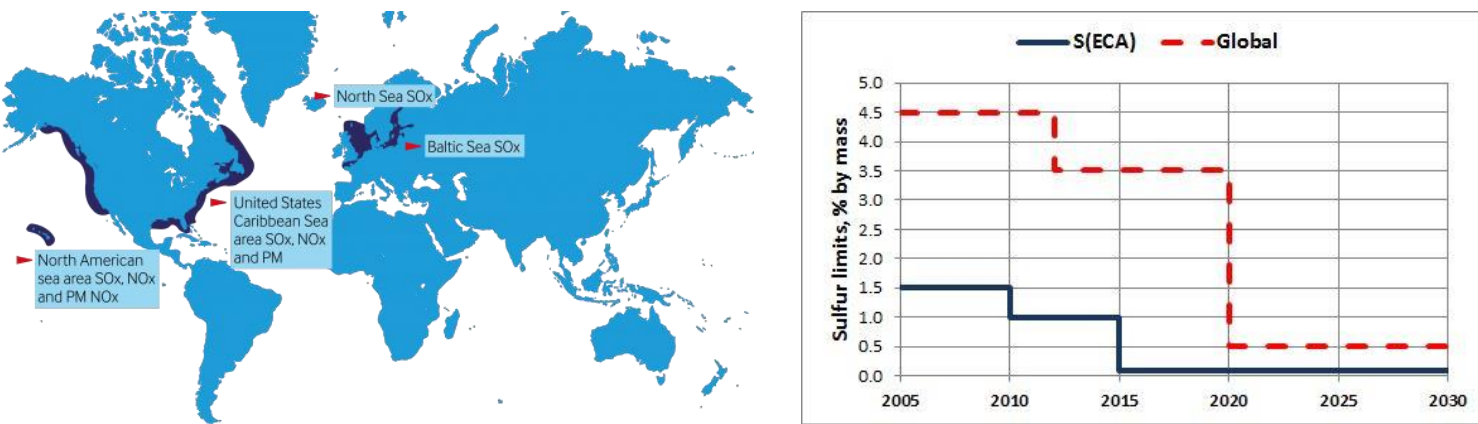

Fig. 1. IMO emission control areas ${ }^{2}$ (left) and changes in sulphur limits by year (right) (DNV-GL, 2019)

Table 2. NOx Emission limits (g/kWh) according to MARPOL Annex VI

\begin{tabular}{|c|c|c|c|}
\hline \multirow{2}{*}{$\begin{array}{c}\text { Engine's } \\
\text { speed (n), RPM }\end{array}$} & \multicolumn{3}{|c|}{ Year of ship build and area of operation } \\
\cline { 2 - 4 } & $2001-2011$ & $\begin{array}{c}\text { After January 1, } \\
2011, \text { in area w/o } \\
\mathrm{NO}_{\mathrm{x}} \text { control }\end{array}$ & $\begin{array}{c}\text { After January 1, } \\
2016, \text { in area with } \\
\mathrm{NO}_{\mathrm{x}} \text { control }\end{array}$ \\
\hline$<130$ & 17.0 & 14.4 & 3.4 \\
\hline $130-2000$ & $45 \mathrm{n}^{(-0.20)}$ & $44 \mathrm{n}^{(-0.23)}$ & $9 \mathrm{n}^{(-0.20)}$ \\
\hline$>2000$ & 9.8 & 7.7 & 2.0 \\
\hline
\end{tabular}

\subsection{Nitrogen oxides}

The environmental problems caused by $\mathrm{NO}_{\mathrm{x}}$ emission are the same as in the $\mathrm{SO}_{\mathrm{x}}$, acid rain. Its formation is associated with the combustion temperature inside the cylinders. The higher the temperature, the greater the emissions. Nitrogen oxide emission limits are applied to all vessels that carry out international voyages and a marine diesel engine with output power greater than $130 \mathrm{~kW}$.

The standards of $\mathrm{NO}_{\mathrm{x}}$ emissions are applied in three distinct categories, depending on the year of construction, and the region of operation of the vessel and engine's rated speed (rpm) as reported in Table 2.

Manufacturers of marine diesel engines have technologies sufficient to reduce the emissions from burning fuel oil to the second category's requirement. In the $\mathrm{NO}_{\mathrm{x}}$ emission control regions, the solution was to replace fuel oil with natural gas, which has a combustion temperature inside the cylinder much lower than diesel, reducing nitrogen oxides by more than $80 \%$.

\subsection{Carbon dioxide}

With the growth of maritime transport, achieving reductions in GHG emissions at the level estimated by the Intergovernmental Panel on Climate Change (IPCC) for 2050 will be practically impossible.

The IMO is working to establish GHG regulations for international transport. It is under pressure from governing bodies such as the European Union and the UNFCCC (United Nations Framework Convention on Climate Change) to apply regulations that will have a significant effect on the emissions (DNV, 2009), leading to Chapter 4 in Annex VI of MARPOL 73/78, presenting $\mathrm{CO}_{2}$ emission standards for new vessels and those already in operation (IMO, 2016).

Technical measures are considered for new vessels, and the improvements are evaluated according to the EEDI. This index's main disadvantages are strongly associated with the cost-effectiveness given that the vessels need to reach the goals established by IMO, considering only technical alternatives.

The operational measures are applied to all vessels and assessed by the Energy Efficiency Operational Indicator (EEOI) by adopting a Ship Energy Efficiency Management Plan (SEEMP). The main 
disadvantage of these mechanisms may be related to the practical implementation due to the need for extensive administration of vessels during their operations.

The EEDI was developed for the largest and most intense segments of the world maritime fleet. The Marine Environment Protection Committee, MEPC developed this index to encourage improvements in fuel consumption, and the main objectives proposed by the committee are:

- Determine a minimum level of energy efficiency for new ships,

- Encourage the continuous technical development of all components that can contribute to fuel efficiency,

- Separate technical and design measures from commercial and operational ones,

- Allow comparison of the energy efficiency between similar vessels and the same size, carrying out the same cargo.

The EEDI establishes a minimum energy efficiency requirement for new ships, depending on their type and size, to gradually increase energy efficiency over a few decades. The index is a nonprescriptive, performance-based mechanism that allows the technology's choice to use a specific ship design by the project's responsible company. If the minimum energy efficiency requirement is reached, the shipyard designers can choose the most economical ship.

Ship-owners, designers, and builders need to meet the increasingly rigid criteria comprising the respective year of construction of the ship, from a reference line that represents the average efficiency for ships between 1999 and 2009 and with the minimum emission reduction limits of $\mathrm{CO}_{2}$, divided into three phases of $10 \%$ for vessels built between 2015 and 2020, 20\% for vessels built between 2020 and 2025 and $30 \%$ for vessels built after 2025 .

The index is mandatory for ships larger than 400 GT (Gross Tonnage). It should be noted, however, that the formulation associated with the index represents the operating profiles of commercial vessels and therefore IMO discusses the possibility of specific formulations for vessels with distinct operational features, such as, for example, operating vessels offshore, which, in contrast with the merchant ship classes, uses a large part of energy in dynamic positioning, during operations on platforms of oil and gas production.

The EEDI index provides a specific measure for each trip taken, subject to the cargo transported, such for example: (tonne of $\mathrm{CO}_{2}$ ) / (tonne - nautical mile), (tonne of $\mathrm{CO}_{2}$ ) / (TEU - nautical mile), etc.

One of this index's objectives is to monitor the vessel's efficiency for each trip it makes and usees the data obtained to carry out the best vessel maintenance and improvement plans to identify possible problems, to predict and schedule preventive maintenance before any failure occurs. All improvements should be included in the SEEMP, allowing the vessel to improve its efficiency gradually.

Adopted on April 13, 2018, was a resolution that reflects the IMO ambition to reduce GHG emissions (MEPC.304(72), 2018).

To satisfy the objectives, the assumption was that shipping would grow towards $150 \%$ (1.2\% per year) or 350\% (3.7\% per year) of the existing fleet in 2050 (de Jong, 2020). The main conclusions for containerships are:

Any serious fleet growth $(>0.4 \%)$ needs more stringent EEDI requirements,

With $3.7 \%$ of the average fleet growth, the container vessel fleet needs zero-emission (8\%) in 2050,

With $3.7 \%$ of the total fleet growth and the current EEDI in effect, the shipping share of greenhouse gas emissions amounts to $130 \%$ rather than the projected $50 \%$ by 2050 .

This pessimistic assessment points to the search for adequate measures to achieve the ambitious plans of the IMO.

\subsection{Trend in pollutant and GHG emissions standards}

The market provides HFO with at least $1 \%$ sulphur, and prohibiting this fuel would significantly increase the demand for MDO and the operating cost fleet since today, the value of marine diesel compared to HFO is at least twice as much. The trend is to postpone the initially specified 2020 norm for $2025 \mathrm{and} /$ or re-evaluate the maximum sulphur limit in the imposed fuel.

Another issue raised at the IMO refers to creating of standards that limit the emission of NMVOC (non-methane volatile organic compounds). These compounds are present in petroleum and their derivatives and are issued in significant quantities by oil and petroleum products, mainly during cargo 
loading. The trend is that the defined maximum NMVOC emission for vessels will come into force after 2025 .

\section{Concept design of container ships operating in the Black Sea}

\subsection{Transportation flow in the Black Sea region}

A recent study presented in (Naydenov \& Georgiev, 2020) analysed the sea transport of intermodal containers in the Black Sea region considered as a part of the corridors between Asia and Europe and an element of the short sea shipping system (Yotsov, et al., 2017). The main traffic and the density can be observed in Fig. 2. More than 50\% of SSS transported goods in the Black Sea are liquid cargoes (https://ec.europa.eu/eurostat/). This may explain the heavy traffic from the port of Odesa to the Bosphorus.

The total growth of the handled containers in the main Black Sea ports in the first half of 2019 was 8.52\% compared to the same period in 2018. In over a month (July 18 and August 18, 2020), Varna, Burgas, Constanta, Odesa, Novorossiysk, Poti and Ambarli were visited by 139 container vessels (Naydenov \& Georgiev, 2020), and 50.4\% of them are classified as small feeder and feeder (up to 2000 TEU capacity).

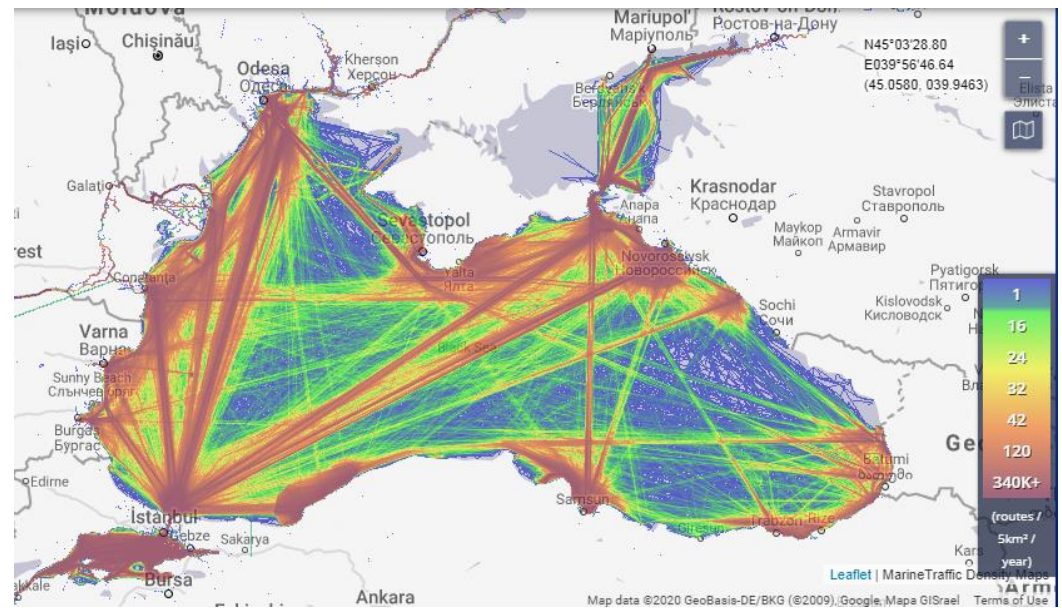

Fig. 2. Ship routes in the Black Sea, end of 2017 (https://www.marinetraffic.com/)

Freight transport in Europe continues to grow, and road transport is expected to increase by around $40 \%$ by 2030 with just over $80 \%$ by 20503 . Therefore, the EU transport policy aims to transform road transport into a less polluting and energy-efficient mode of transportation. The Council Directive 92/106/EEC (Combined Transport Directive) introduces several support measures. One of the "regulatory" support measures is the use of 45 -foot containers.

The 45 -foot-high cube pallet wide container is more extensive $\left(89 \mathrm{~m}^{3}\right.$ vs $76.4 \mathrm{~m}^{3}$ for FEU). It is slightly wider and much longer than a standard 40ft high cube container. Therefore, two-euro pallets can be loaded side by side, providing the stowage of 26 standard pallets $(1,00 \times 1,20 \mathrm{~m})$ and 33 Euro pallets $(0.80 \times 1.20)$.

The recent development of short sea shipping in the Black Sea region has shown that intermodal transportation will play an important role. Concurrently, however, the Black Sea region's coaster fleet is of considerable age, and the increased freight rates enforce new orders of ships. (Damyanliev , et al., 2021).

\footnotetext{
${ }^{3}$ https://ec.europa.eu/transport/themes/logistics-and-multimodal-transport/multimodal-and-combined-transport_en
} 


\subsection{Assignment of the concept design}

The study here presents the concept design of series of containerships operating in the Black Sea for transporting 20, 40 and 45-foot containers identifying the main dimensions, capacity, visibility, freeboard, stability, bow, and stern design, propulsion, and propeller design, control and manoeuvrability, seakeeping, EEDI, capital expenditure CAPEX and operational expenditures, OPEX, that leads to the required fright rate for the ships in the range of 4,000 to 14,000 DWT satisfying the requirement for EEDI.

The surveyed Black Sea routes are displayed in Fig. 3 and Table 3. One of the principal objectives of the study is to compare the effectiveness of different modes of transportation using different size containers. The demand for transported cargo is given in tonne instead of the number of containers needed for this purpose. It is assumed that only $60 \%$ of the cargo capacity of containers is used for cargo transportation. The 20,40, and 45-foot containers carry $13.2,15.8$, and 18.3 tonnes, respectively.

Table 3. Analysed Black Sea routes

\begin{tabular}{|c|c|c|c|}
\hline Indicator & Routes & Distance, $\mathbf{n m}$ & Cargo demand, tonne \\
\hline $\boldsymbol{\psi}=\mathbf{1}$ & Varna-Poti & 613 & $2,000,000$ \\
\hline $\boldsymbol{\psi}=\mathbf{2}$ & Varna-Istanbul & 149 & $1,000,000$ \\
\hline $\boldsymbol{\psi}=\mathbf{3}$ & Varna-Novorossiysk & 440 & 500,000 \\
\hline $\boldsymbol{\psi}=\mathbf{4}$ & Varna-Odessa & 244 & 500,000 \\
\hline
\end{tabular}

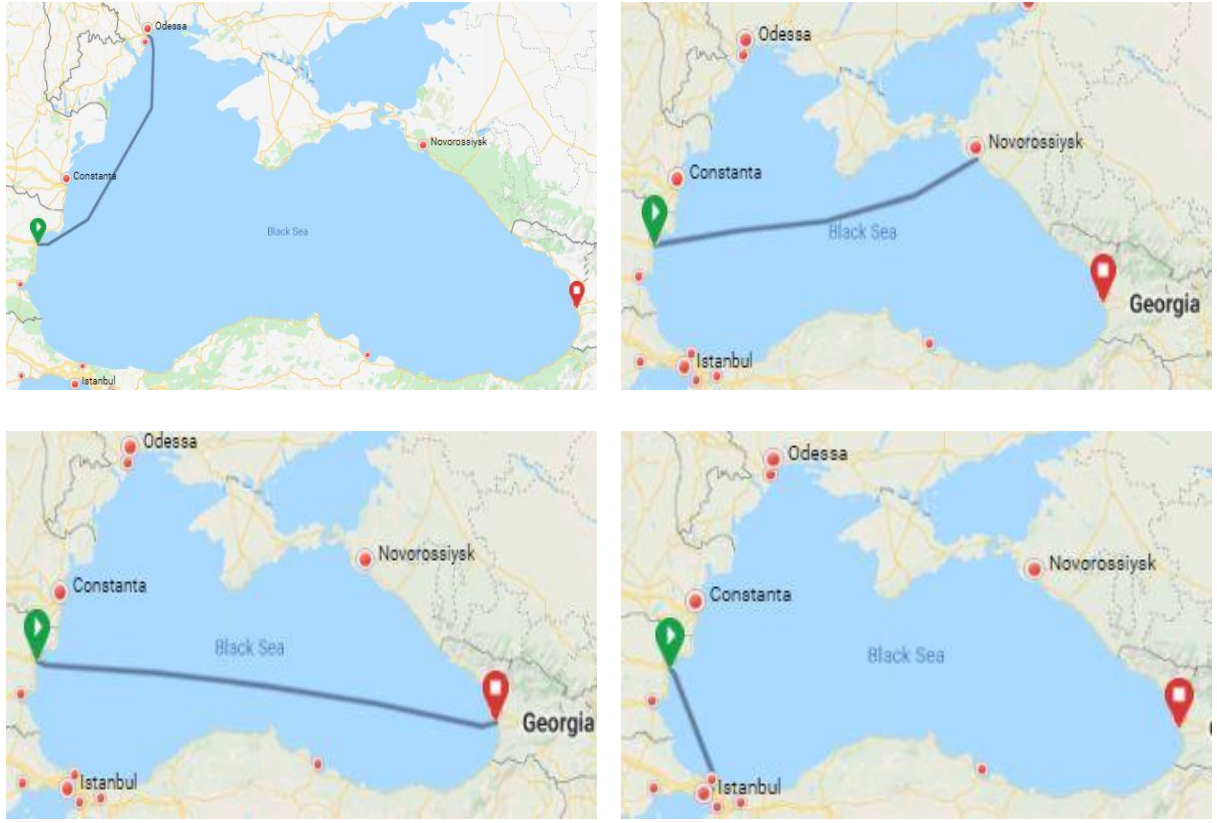

Fig. 3. Considered Black Sea routes

An extra slow steaming speed of ships of Vs=14 knots, known as a super slow steaming and economical speed, is applied on specific short-distance routes achieving a minimal level of fuel consumption while still maintaining a commercial service. Consequently, this is the speed that serves as an agreed reference for the present study.

The design constraints are depicted in Table 4. An additional limitation about the minimum engine power is included to guarantee the engine power is sufficient to perform satisfactory manoeuvring in severe weather conditions (Barr, et al., 1981).

The estimated DWT and number of containers in Fig. 4 as a function of ship length for the ships under study are outlined and the ship cargo and ballast in Fig. 5. It should be emphasised, however, that in Fig. 5, at the right side, may show a negative value of the ballast, indicating a reduction of the 
maximum cargo capacity in tonnes to satisfy the static equilibrium condition and stability requirements of any particular ship and DW distribution along with the ship length and depth.

Table 4. Constraints

\begin{tabular}{|c|c|c|c|}
\hline $\min$ & \multicolumn{2}{|c|}{ Description } & $\max$ \\
\hline 5.0 & \multicolumn{2}{|c|}{$L_{p p} / B$} & 5.3 \\
\hline 9.6 & \multicolumn{2}{|c|}{$L_{p p} / D$} & 11.5 \\
\hline 2.5 & \multicolumn{2}{|c|}{$B / T$} & 3.6 \\
\hline 1.5 & \multicolumn{2}{|c|}{$B / D$} & 2.5 \\
\hline 60 & \multicolumn{2}{|c|}{ Propeller speed, rpm } & 120 \\
\hline 0.35 & \multicolumn{2}{|c|}{ Propeller expanded area ratio } & 1.05 \\
\hline 0.5 & \multicolumn{2}{|c|}{ Pitch ratio } & 1.4 \\
\hline & EEDI & \multicolumn{2}{|c|}{ To be satisfied } \\
\hline & Stability & \multicolumn{2}{|c|}{ To be satisfied } \\
\hline & Freeboard & \multicolumn{2}{|c|}{ To be satisfied } \\
\hline & Seakeeping & \multicolumn{2}{|c|}{ To be satisfied } \\
\hline & Manoeuvrability & \multicolumn{2}{|c|}{ To be satisfied } \\
\hline & Cavitation & \multicolumn{2}{|c|}{ To be satisfied } \\
\hline & Visibility & \multicolumn{2}{|c|}{ To be satisfied } \\
\hline & Weigh distribution & \multicolumn{2}{|c|}{ To be satisfied } \\
\hline & er bending moment & \multicolumn{2}{|c|}{ To be satisfied } \\
\hline
\end{tabular}
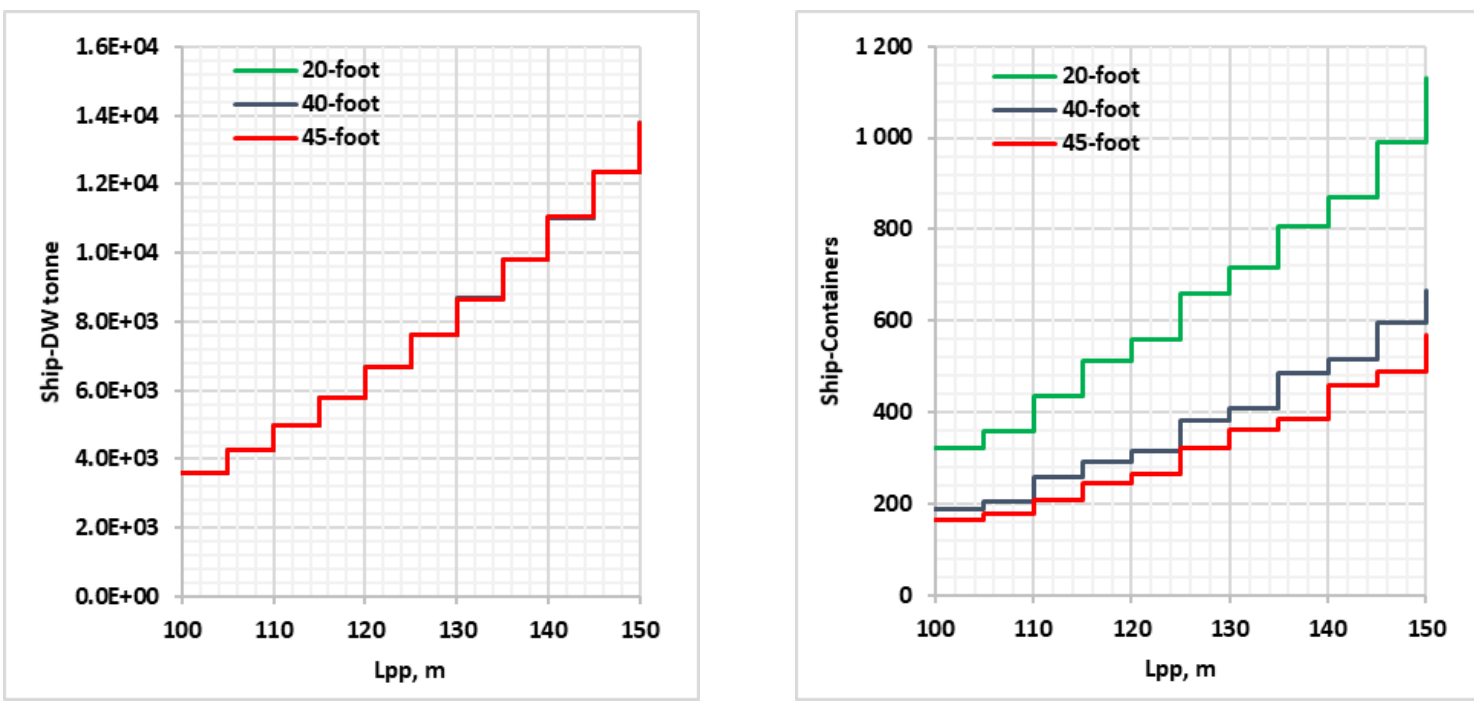

Fig. 4. Ship- DWT (left) and number of containers (right) as a function of ship length, $\psi=1$. 

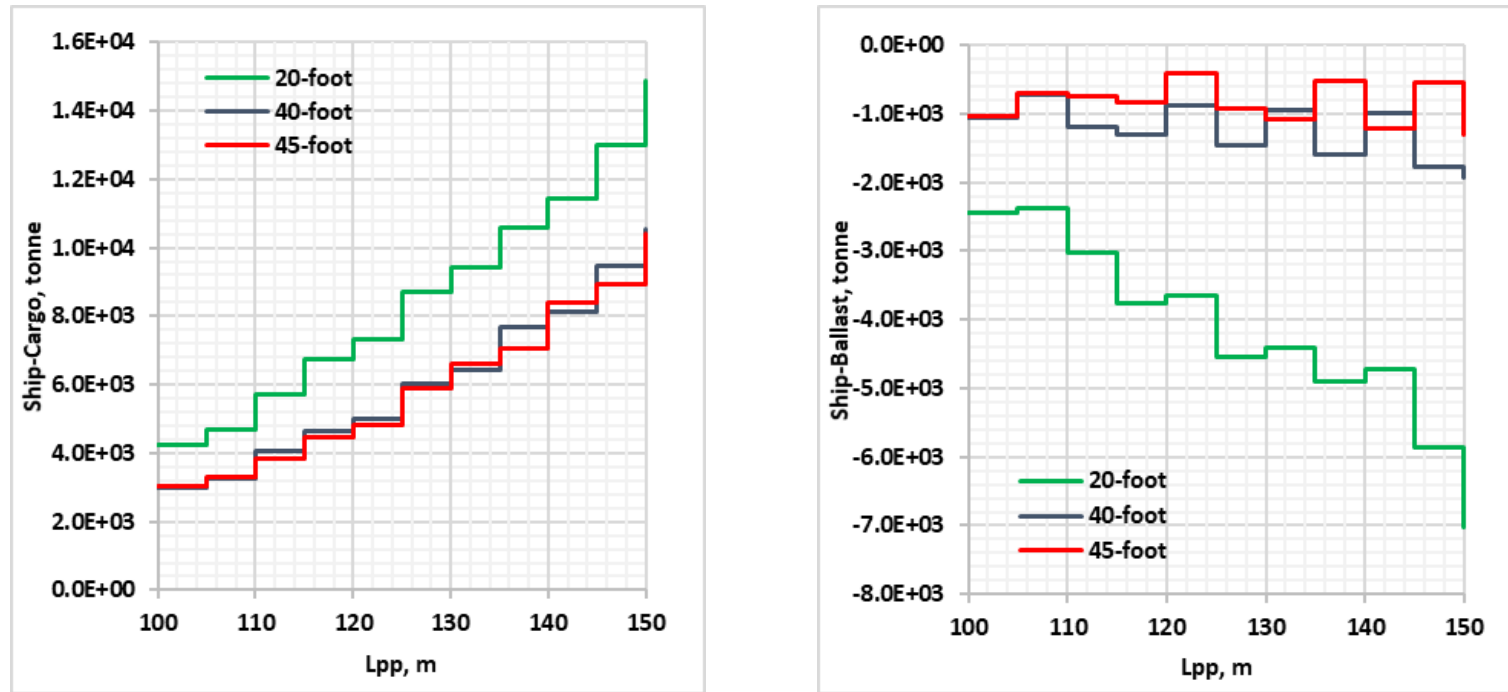

Fig. 5. Ship- cargo (left) and ballast (right) as a function of ship length, $\psi=1$.

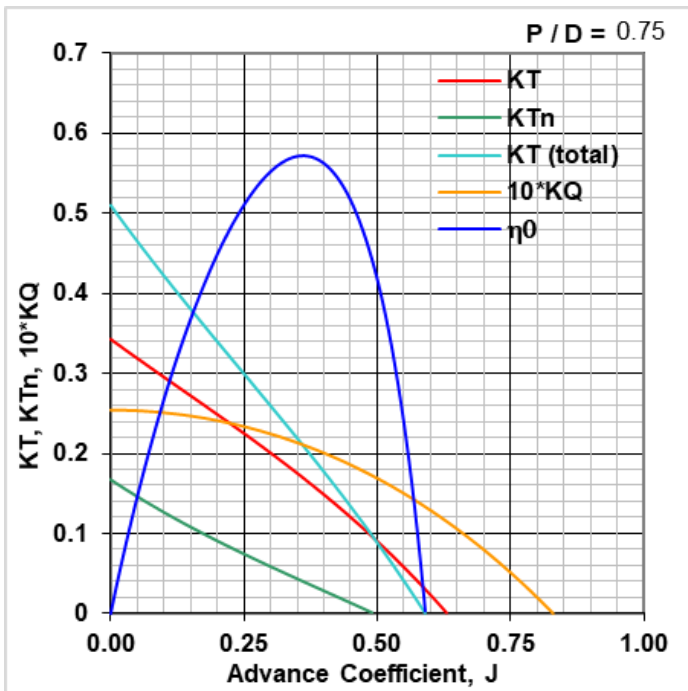

Fig. 6. Propeller design, $\psi=1, L_{p p}=150 \mathrm{~m}, B=28.30 \mathrm{~m}, D=13.04 \mathrm{~m}, T=7.86 \mathrm{~m}, C_{b}=0.63, V_{s}=14$ knots. 

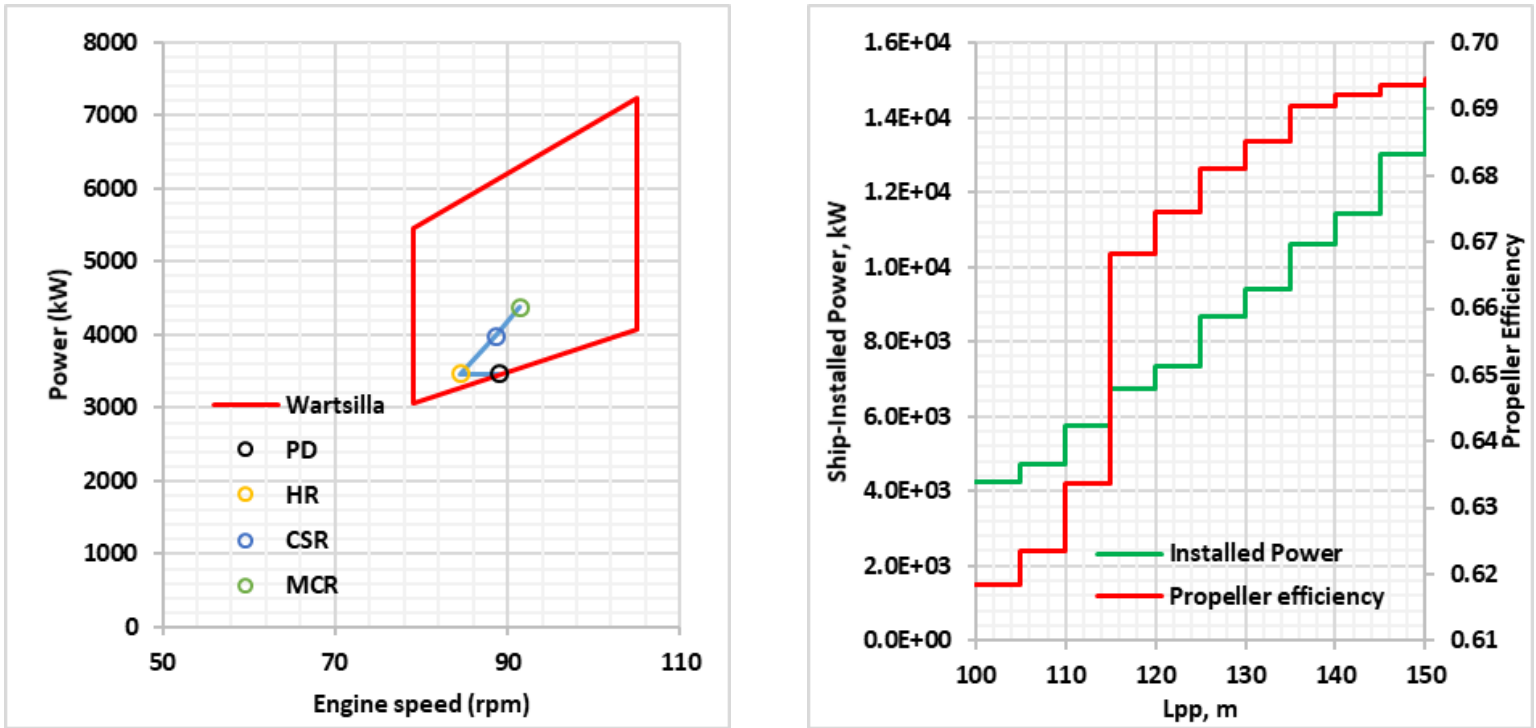

Fig. 7. Ship-propeller-motor match, $L_{p p}=150 \mathrm{~m}, B=28.30 \mathrm{~m}, D=13.04 \mathrm{~m}, T=7.86 \mathrm{~m}, C_{b}=0.63, V_{s}=14$ knots (right) and installed power as a function of ship length, $\psi=1$.

Once the open water efficiency has been determined, the engine's brake power can be calculated by the energy chain of propulsion (Woud \& Stapersma, 2002) as shown in Fig. 6, and to solve the matching problem, adopted is the looping approach. For the ship's predefined speed, combined with the engine information, adequate ship power is estimated. Once the calculated ship sufficient power is equal to the given one, the propulsion system's balance is met, as shown in Fig. 7.

The CAPEX may or may not be involved as an initial purchase capital, and the periodic cash payments to banks or investors and the cash received from the sale of the vessel are presented in Fig. 8.

The trade route analysis plays a significant role in the ship design and the restricted draft conditions to define the cargo availability and the necessary fuel oil, etc., in addition to the total annual cost. As for the ship operation time, $\mathrm{T}_{\text {operation }}=350$ days per year are prescribed, with the remaining days being devoted to shipyard repairs. Ships with faster port turnaround have less time for dockside repairs and may require an additional ten days' repair time per year.

The operating costs are the ongoing expenses connected with the vessel's day-to-day running (excluding fuel, which is included in voyage costs), together with an allowance for everyday repairs and maintenance. The principal components of operating expenses include manning cost, stores, routine repair and maintenance, insurance, and administration. The annual operating cost is explicated in Fig. 8.

The agreed fuel oil price is $€ 350$ per tonne, and that of the diesel oil is $€ 370$ per tonne. The annual fuel cost is represented in Fig. 9. The ship's fuel consumption depends on the speed, assumed here as $\mathrm{V}_{\mathrm{s}}=14$ knots, and distance at which the ship is under operation.

As can be seen from Fig. 8, the ship construction and operating cost for transporting the same cargo by 20, 40 and 45-foot containers are the same, satisfying the constraints presented in Table 4. Constraints however, examining the utilisation of the under-deck cargo space in greater detail, it seems that the 20-foot containers are more adjustable to the limited space as a function of the ship's main dimensions. As a result, fewer ship annual round voyages and ship annual fuel costs are estimated in ships transporting the same cargo using 20-foot containers. Additionally, the ship discounted, the average yearly cost, and the required fright rate for 40 and 45 -foot containers is higher than 20 -foot containers are presented in Fig. 10. Similar conclusions can be derived for the rest of the routes analysed, $\psi=2,3$ and 4 . 
ISSN 2603-316X (Online)
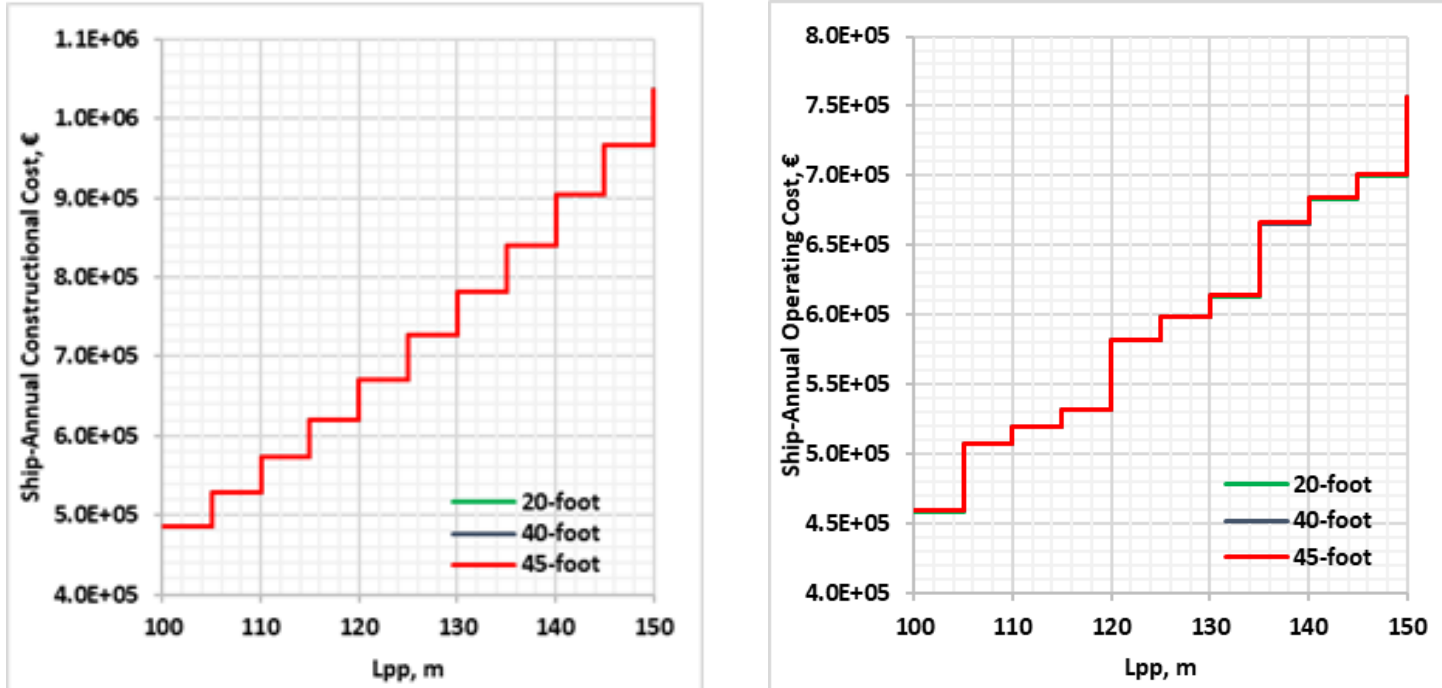

Fig. 8. Ship-annual constructional cost as a function of ship length (left) and ship-annual operating cost as a function of ship length (right), $\psi=1$.
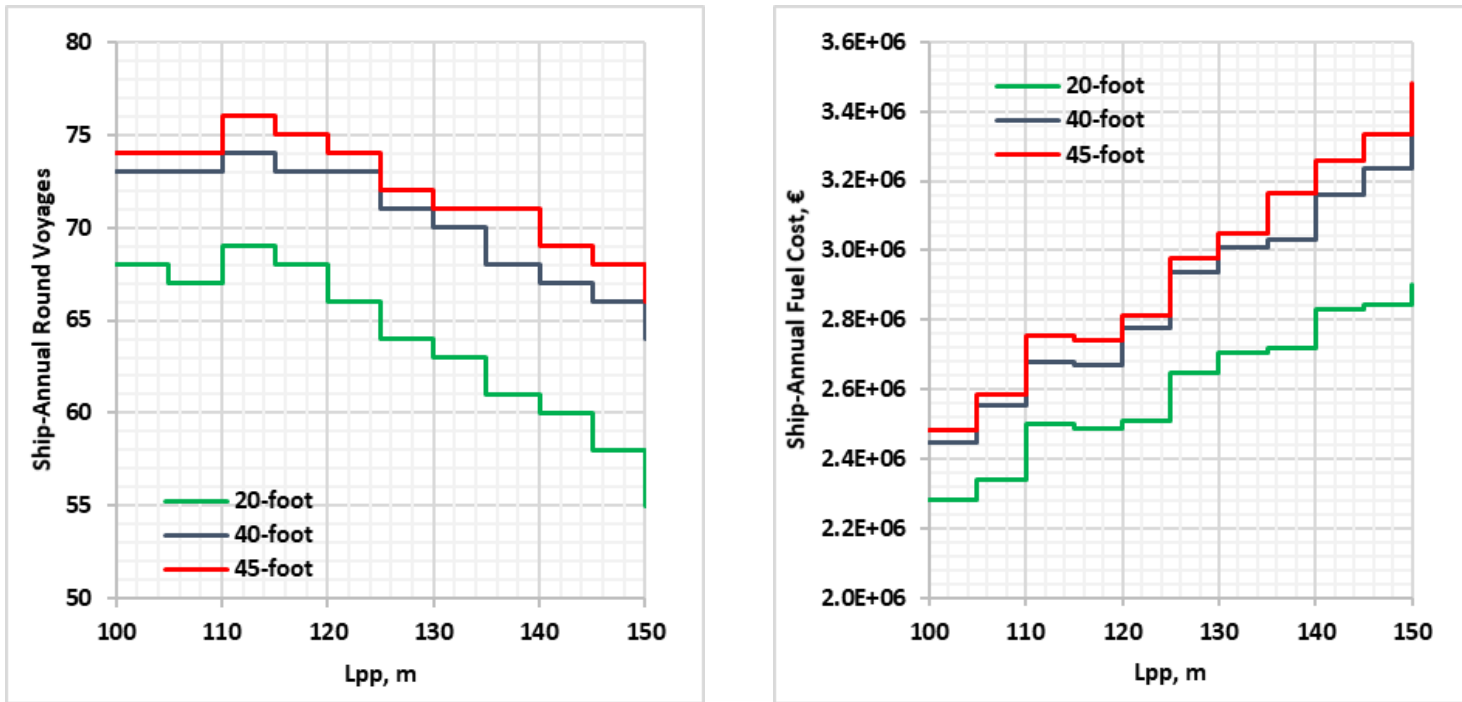

Fig. 9. Ship-annual round voyages (left) and fuel cost (right) as a function of ship length, $\psi=1$.
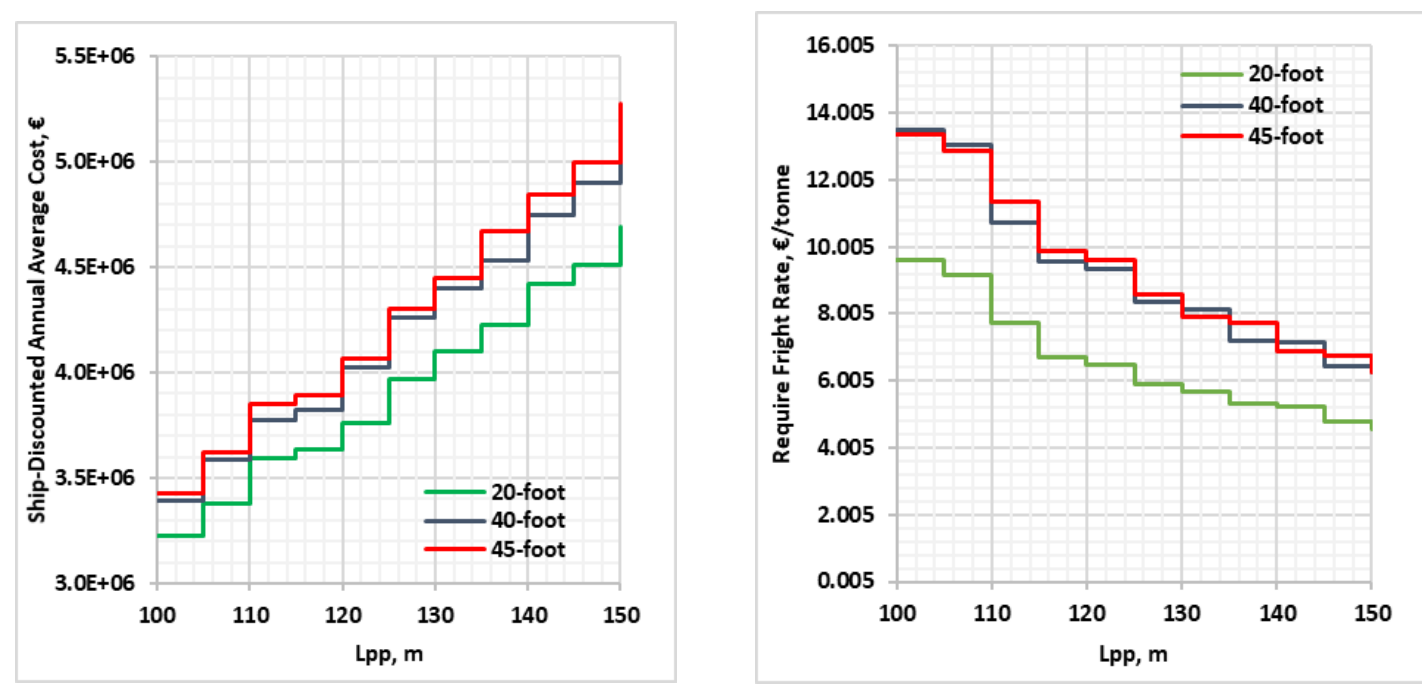

Fig. 10. Ship-discounted annual average cost (left) and required fright rate (right) as a function of ship length, $\psi=1$. 


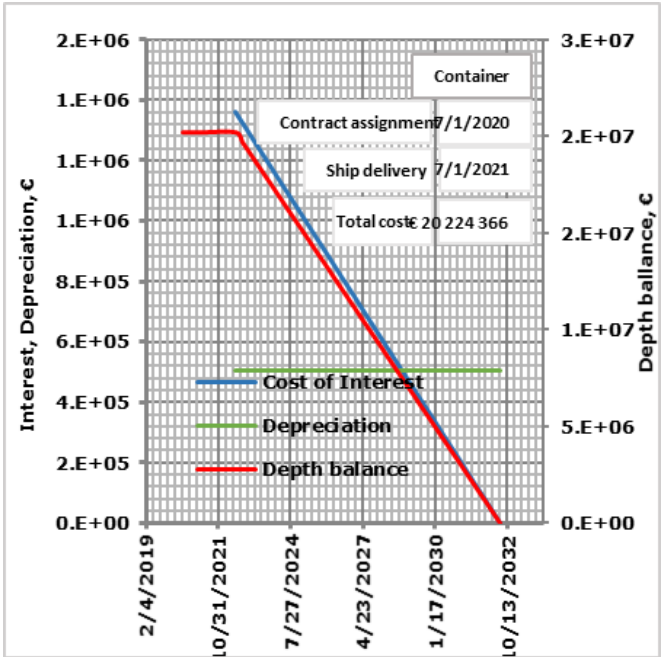

Fig. 11. Depreciation and depth balance, $\psi=1, L_{p p}=150 \mathrm{~m}, B=28.30 \mathrm{~m}, D=13.04 \mathrm{~m}, T=7.86 \mathrm{~m}, C_{b}=0.63$, $V_{s}=14$ knots.

The depreciation reflects the loss of performance due to age, higher maintenance expenses, a level of technical obsolescence, and expectations about the economic life of the vessel. It represents the ship's equivalent in money when the project started. It is just bookkeeping, so profit will be lower than cash flow by that amount. It has been estimated that the capital recovery period is 19.52 years, assuming that the residual value is $5 \%$ and depreciation time is 15 years. The depreciation and depth balance of the vessels within 20 years is shown in Fig. 11.

\section{$4 \quad$ Risk-based design considering EEDI}

As stipulated in (IMO, 2013), the FSA methodology as is summarised in Fig. 12, is elaborated under IMO's auspices based on a Quantified Risk Analysis, QRA, and provides a broad application of QRA to marine transportation. It is a methodology to enhance maritime safety, including protecting life, health, the maritime environment, and life-cycle cost.

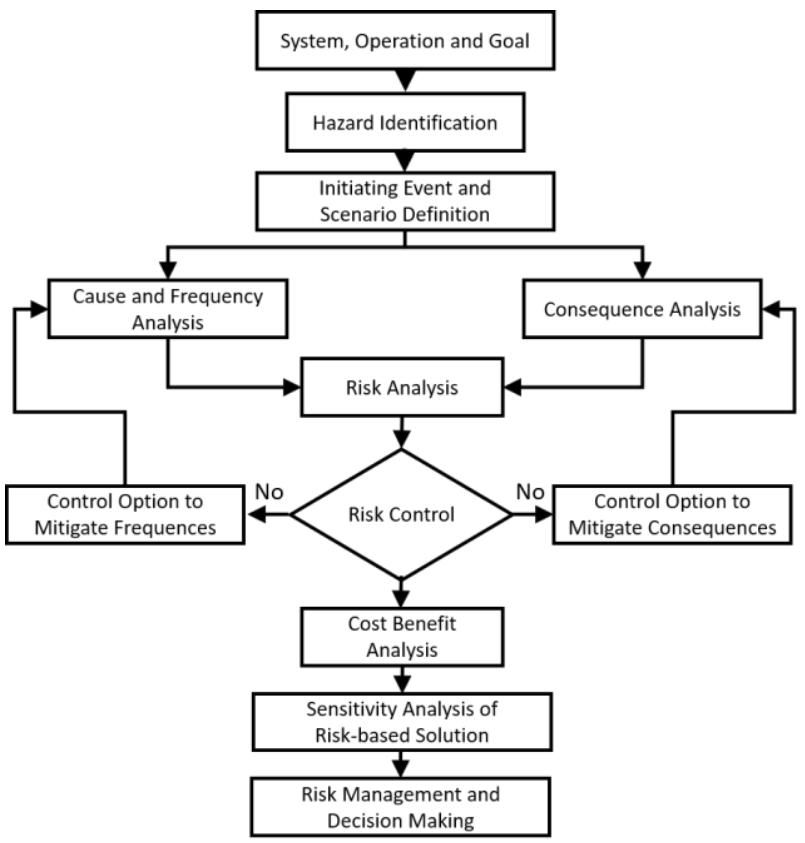

Fig. 12. Formal Safety Assessment 
A bulk carrier's risk-based concept ship design methodology was employed (Garbatov \& Georgiev, 2021), accounting for the ship propulsion complex's life cycle assessment and energy efficiency. The study included conceptual ship design as a part of the risk-based ship design solution.

Three objective functions were defined to minimise the lightship weight and transportation cost and maximise the annual cargo income. The design governing parameters are given in Table 5 and constraints in Table 6. An additional limitation to the minimum engine power is included to guarantee the engine power is sufficient enough to perform satisfactory manoeuvring in severe weather conditions (Barr, et al., 1981)

Table 5. Bulk carrier design governing parameters

\begin{tabular}{|c|c|c|}
\hline Lower & Decision Variables & Upper \\
\hline 150.00 & $\leq L_{p p}(\mathrm{~m}) \leq$ & 274.32 \\
\hline 20.00 & $\leq B(\mathrm{~m}) \leq$ & 32.31 \\
\hline 13.00 & $\leq D(\mathrm{~m}) \leq$ & 25.00 \\
\hline 10.00 & $\leq T(\mathrm{~m}) \leq$ & 11.71 \\
\hline 0.63 & $\leq C_{b} \leq$ & 0.75 \\
\hline 8.00 & $\leq V_{s}($ knots $) \leq$ & 16.00 \\
\hline
\end{tabular}

Table 6. Bulk carrier constraints

\begin{tabular}{|c|c|c|}
\hline Constraints & Description & Values \\
\hline$L / B$ & Greater & 5.0 \\
\hline$L / D$ & Lesser & 12.5 \\
\hline$L / T$ & Lesser & 24.0 \\
\hline$F_{n}$ & Lesser & 0.32 \\
\hline$D W, \mathrm{t}$ & Greater & 25,000 \\
\hline$D W, \mathrm{t}$ & Lesser & 35,000 \\
\hline$T-0.45 D W^{0.31}$ & Lesser & 0.00 \\
\hline$T-0.7 D-0.7, \mathrm{~m}$ & Lesser & 0.00 \\
\hline Engine Power $(\mathrm{kW})$ & Greater & $0.0763 D W+3.374$ \\
\hline Stability & To be satisfied & \\
\hline Freeboard & To be satisfied & \\
\hline Seakeeping & To be satisfied & \\
\hline Manoeuvrability & To be satisfied & \\
\hline
\end{tabular}

NSGA-II (Deb, et al., 2002) is applied to ensure that the optimal solution can be obtained quickly with sufficient quantity and accuracy. The Pareto Frontier (Horn, et al., 1994; Komuro, et al., 2006), defines all optimal solutions represented in the design space, related to the 90 acceptable design solutions as a function of the lightship weight, with the annual cargo and transportation cost being presented in the 3D diagram in Fig. 13. The triangular symbols in Fig. 13 denote the relationship between lightship weight and transportation cost. The circle represents the relationship between the annual cargo and transportation costs. The rectangular symbols represent the relationship between the yearly cargo and lightship weight, and the solid circles represent the 3D relationship between the three variables.

As exemplified in Fig. 14, for all acceptable design solutions, the relatively longer ships indicate a lower level of EEDI, which can be explained by the slender hull form that creates a lower resistance. Increasing the draft can considerably reduce the EEDI. The increasing speed is highly sensitive to the EEDI since the required power is in the service speed's direct function. Reducing the service speed may reduce the EEDI, but this is conditional on the ship's manoeuvrability capacity. 


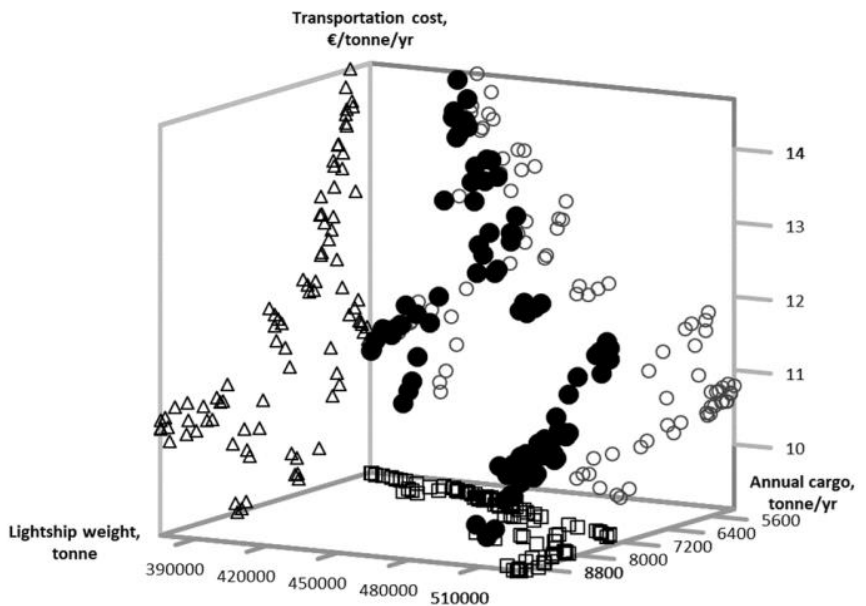

Fig. 13. Pareto frontier of acceptable design solutions.

The required EEDI ${ }_{\text {req }}$ adjusted to be used after 2020 is $5.3 \mathrm{gCO}_{2}$ /tonne-mile for the bulk carrier ships. The optimal risk-based design solution is $\mathrm{n}^{\mathrm{0}}=3$, as shown in Fig. $\mathbf{1 4}$ and its descriptors sum up in Table 7. Ship characteristics of optimal risk-based design solution, $n^{0}=3$. The encountered design solution does not presuppose enhancing the propulsion system and any other engineering solution in reducing the $\mathrm{gCO}_{2} /$ tonne-mile.

For this ship design solution $\left(\mathrm{n}^{\mathrm{o}}=3\right)$, some measures, including the hull lines optimisation, main engine and propeller alternatives, energy-saving devices, and rudder arrangement, are needed (Garbatov \& Georgiev, 2021).
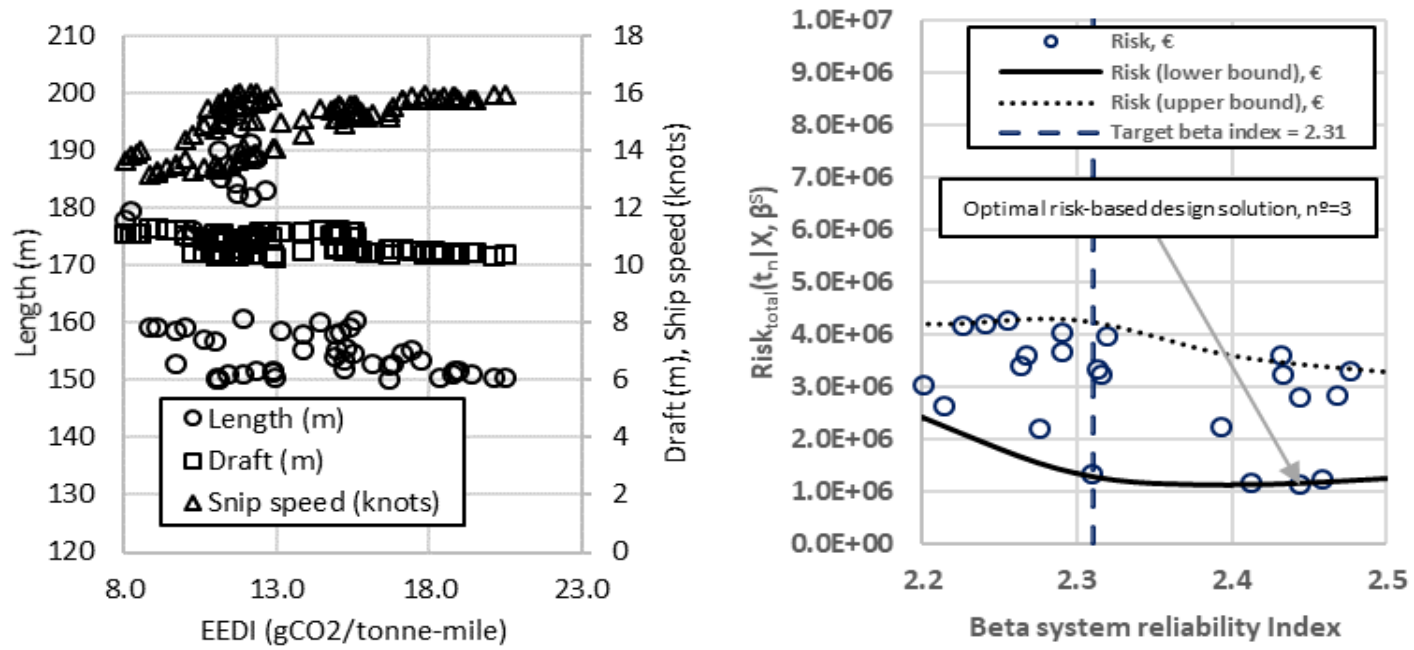

Fig. 14. Length, draft, and ship speed as a function of EEDI (left), optimal risk-based design solution, $n^{\circ} 3$, $E E D I=7.9 \mathrm{gCO}_{2}$ /tonne-mile $V_{s}=13.55$ knots (right)

The risk-based ship design of a bulk carrier accounting for EEDI was based on hull form, resistance and propulsion, weights, initial stability, freeboard, seakeeping and manoeuvrability, and CAPEX, OPEX and DECEX. At the concept stage, an optimal design solution was defined using EEDI, shipbuilding, operation, and resale costs at the end of the service life, as an input variable in the risk estimate. 
Table 7. Ship characteristics of optimal risk-based design solution, $\mathrm{n}^{\mathrm{o}}=3$

\begin{tabular}{|c|c|c|c|}
\hline$L_{p p}, \mathrm{~m}$ & 179.1 & $L / B$ & 5.82 \\
\hline$B, \mathrm{~m}$ & 32.08 & $L / D$ & 12.06 \\
\hline$D, \mathrm{~m}$ & 14.84 & $L / T$ & 16.15 \\
\hline$T, \mathrm{~m}$ & 11.08 & $F_{n}$ & 0.166 \\
\hline$C_{b}$ & 0.65 & $L W$, tonne & 7,580 \\
\hline$V_{s}, \mathrm{kn}$ & 13.55 & $A C,($ tonne/yr $)$ & 479,964 \\
\hline$D W$, tonne & 34,926 & $T C,(€ /$ tonne $)$ & 9.12 \\
\hline
\end{tabular}

Using a classical ship design approach appropriate to bulk carriers, the IMO stipulated maximum value of the required EEDI may lie below the estimated index value for the ship. One reason might be the inappropriate engine selection, hull form, unacceptable service, type, and fuel consumption. On balance, several possible solutions for reducing the effects of $\mathrm{CO}_{2}$ emission have been considered, including propulsion power, ship speed and displacement, specific fuel oil consumption, LW/LBD relation, and ship design speed. More detail about this study is provided in (Garbatov \& Georgiev, 2021)

\section{Conclusions}

The mitigation of the different environmental impacts caused by maritime transport requires a review of the ships' design considering the vessel's life cycle, the critical importance of the environmental criterion, the technical criteria and economic specific ones in ship design.

The risk-based ship design, including EEDI, can produce an acceptable design solution. The effect of EEDI is estimated relative to the hull form, resistance and propulsion, weights, initial stability, freeboard, seakeeping and manoeuvrability, and CAPEX, OPEX and DECEX. At the concept stage, an optimal design solution can be determined by EEDI, shipbuilding, operation, and resale costs at the end of the service life, as an input variable in the risk estimate.

Using a classical ship design approach, the IMO stipulated maximum value of the required EEDI may lie below the estimated index value for the ship, and one of the reasons may be the inappropriate engine selection, hull form, unacceptable service, type, and fuel consumption. Finally, several possible solutions for reducing the effects of $\mathrm{CO}_{2}$ emission may be considered, including propulsion power, ship speed and displacement, specific fuel oil consumption, LW/LBD relation, and ship design speed.

The multi-objective mathematical optimisation method is esteemed as a valuable tool that may enhance the quality of the conceptual design solution by providing the rationale for the naval architectural design aspects, environment, reliability, and risk throughout the vessel's life cycle.

Shipping companies should evaluate the reduction of fuel consumption and the emission of pollutants emanating from the main and auxiliary engines, pursuant to the resizing of speed and number of ships in the fleet, following the required investments.

\section{Acknowledgements}

This work was performed within Project NP8/2020 from the Research Plan of the Technical University of Varna, financed by the State Budget.

\section{References}

Barr, R., Miller, E., Ankudinov, V., \& Lee, F. (1981). Technical Basis for Maneuvering Performance Standards. Defense Technical Information Center.

Bergström, M., Erikstad, S., \& Ehlers, S. (2016). Assessment of the applicability of goal- and riskbased design on Arctic sea transport systems. Ocean Engineering, 128, pp. 183-198. 
Blasco, J., Durán-Grado, V., Hampel, M., \& Moreno-Gutiérrez, J. (2014). Towards an integrated environmental risk assessment of emissions from ships' propulsion systems. Environment International, 66, pp. 44-47.

Boulougouris, E., Papanikolaou, A., \& Pavlou, A. (2011). Energy efficiency parametric design tool in the framework of holistic ship design optimisation. Part M: Journal of Engineering for the Maritime Environment, 225(3), pp. 242-260

Damyanliev , T., Georgiev, P., Denev, Y., Naydenov , L., Garbatov, Y., \& Atanasova, I. (2021). Short sea shipping and shipbuilding capacity of the East Mediterranean and Black Sea regions. In C. Guedes Soares, \& T. A. Santos, Developments in Maritime Technology and Engineering (p. In print). London: Taylor\&Francis.

de Jong, J. (2020). Better Ships, Blue Oceans. In INTERNATIONAL CONFERENCE.Influence of EEDI on Ship Design \& Operation. London: RINA.

Deb, K., Pratap, A., Agrawal, S., \& Meyarivan , T. (2002). A Fast and Elitist Multi-objective Genetic Algorithm: NSGA-II. IEEE Transactions on Evolutionary Computation, 6, pp. 182-197.

DNV. (2009). MARPOL 73/78 Annex VI - Regulations for the Prevention of Air Pollution from Ships: Technical and Operational Implications. Hovik: DNV.

DNV-GL. (2019, March 12). Sulphur limit in ECAs - increased risk of PSC deficiencies and detentions. Retrieved 12 15, 2020, from https://www.dnvgl.com/news/sulphur-limit-in-ecasincreased-risk-of-psc-deficiencies-and-detentions-142911

Fenhann, J. (2017). CO2 Emissions from International Shipping. UNEP DTU Partnership Working Paper Series, 4.

Garbatov, Y., \& Georgiev, P. (2021). Risk-based conceptual ship design of a bulk carrier accounting for energy efficiency design index (EEDI). International Journal of Maritime Engineering, Part A, 163, pp. A51-A62

Garbatov, Y., Sisci, F., \& Ventura, M. (2018a). Risk-based framework for ship and structural design accounting for maintenance planning. Ocean Engineering, 166, pp. 12-25.

Garbatov, Y., Ventura, M., Guedes Soares, C., Georgiev, P., Kosh, T., \& Atanasova, I. (2018b). Framework for conceptual ship design accounting for risk-based life cycle assessment. In C. Guedes Soares, \& A. Teixeira (Eds.), Maritime transportation and harvesting of sea resources pp. 921-931. London: Taylor\&Francis.

Horn, J., Nafliotis, N., \& Goldberg, D. (1994). A niched Pareto genetic algorithm for multi-objective optimisation. In First IEEE Conference on Evolutionary Computation (Ed.). 1, pp. 82-87. Piscataway, NJ: IEEE Service Center.

IMO. (2002). Consolidated text of the guidelines for formal safety assessment (FSA) for use in the IMO rule-making process. MSC/Circ.1023/MEPC/Circ.392. London: International Maritime Organization Publishing.

IMO. (2005). Amendments to the guidelines for formal safety assessment (FSA) for use in the IMO rule-making process. MSC/Circ.1180-MEPC/Circ.474. London: International Maritime Organization Publishing.

IMO. (2008a). Formal safety assessment on crude oil tankers. London: International Maritime Organization Publishing. 
IMO. (2008b). Prevention of Air Pollution from Ships: Updated 2000 Study on Greenhouse Gas Emissions from Ships. London: IMO.

IMO. (2013). Revised guidelines for formal safety assessment (FSA) for use in the IMO rule-making process.MSC-MEPC.2/Circ.12. London: International Maritime Organization Publishing.

IMO. (2016). IMO train the Trainer (TTT) Course on Energy Efficient Ship Operation: Module 2 Ship Energy Efficiency Regulations and Related Guidelines. London: IMO.

Kågeson, P. (1999). Economic instruments for reducing emissions from sea transport. Solna, Sweden: Williamson Offset.

Komuro, R., Ford, E., \& Reynolds, J. (2006). The use of multi-criteria assessment in developing a process model. Ecological Modelling, 197, pp. 320-330.

Lindstad, E., \& Bø, T. (2018). Potential power setups, fuels and hull designs capable of satisfying future EEDI requirements. Transportation Research Part D, 63, pp. 276-290.

MEPC.304(72). (2018). Initial IMO strategy on reduction of GHG emisions from ships. London: MEPC.

Naydenov, L., \& Georgiev, P. (2020). Prospects for sea transport of intermodal containers in the Black Sea. Fifteenth International Conference on Marine Sciences and Technologies - the Black Sea 2020, pp. 97-105. Varna: Varna Scientific and Technical Unions.

Nowacki, H. (2019). On the History of Ship Design for the Life Cycle. In A. Papanikolaou (Ed.), A Holistic Approach to Ship Design. pp. 43-74. Athens: Springer.

Papadimitriou, S., Koliousis, I., Sdoukopoulos, E., Lyridis, D., Tsioumas, V., \& Stavroulakis, P. (2018). The Dynamics of Short Sea Shipping. New Practices and Trends. Cham, Switzerland: Palgrave Macmillan.

Papanikolaou, A., Guedes Soares, C., Jasinowski, A., Jensen, J., McGeorge, D., Poylio, E., et al. (2009). Risk-Based Ship Design. Heidelberg: Springer.

Plessas, T., Kanellopoulou, A., Zaraphonitis, G., Papanikolaou, A., \& Shigunov, V. (2018). Exploration of design space and optimisation of RoPax vessels and containerships in view of EEDI and safe operation in adverse sea conditions. Ocean Engineering, 162, pp. 1-20.

Rodrigue, J.-P. (2020). The Geography of Transport Systems (5 ed. ed.). New York: Routledge.

Smith, T., Raucci, C., Haji Hosseinloo, S., Rojon, I., Calleya, J., Suárez de la Fuente, S., et al. (2016). $\mathrm{CO} 2$ emissions from international shipping. Possible reduction targets and their associated pathways. London: UMAS.

Tan, X., Taob, J., \& Konovessis, D. (2019). Preliminary design of a tanker ship in the context of collision-induced environmental-risk-based ship design. Ocean Engineering, 181, pp.185-197.

UNCTAD. (2020). Review of Maritime Transport 2019. Geneva: UNCTAD.

Woud, K., \& Stapersma, D. (2002). Design of propulsion and electric power generation systems. London: IMarEST.

Yotsov, I., Dimitrakiev, D., Zaburtov, A., \& Koritarov, T. (2017). Analysis of the Logistics Transport Corridors in Black Sea ReGion Based on the Short Sea Shipping Concept. Varna: International Association of Maritime Universities. 